\title{
Cortical activation in alexithymia as a response to emotional stimuli
}

Hasse Karlsson, Petri Näätänen and Hanna Stenman

\section{Background}

Alexithymia has been shown to be related to many psychiatric and somatic illnesses. Aberrant emotion processing in the brain may underlie several psychiatric disorders. However, little is known about the neurobiological underpinnings of alexithymia.

\section{Aims}

To determine the way in which the brain processes emotion in alexithymia.

\section{Method}

The participants were 10 healthy women with alexithymia and 11 healthy women without this condition, recruited into the study on the basis of their scores on the 20-item Toronto Alexithymia Scale. Four films were projected on a video screen to induce each of three emotional conditions (neutral, amusement, sadness). The brain areas activated during emotional stimuli in the alexithymia group were compared with those activated in the non-alexithymia group. Scans of the distribution of $\left[{ }^{15} \mathrm{O}\right] \mathrm{H}_{2} \mathrm{O}$ were acquired using a positron emission tomography (PET) scanner operated in threedimensional mode.

\section{Results}

In response to emotional stimuli participants with alexithymia activated more parts of their sensory and motor cortices and insula, especially on the left side, and less of their anterior cingulate, compared with the control group.

\section{Conclusions}

Women with alexithymia seem to over-activate their 'bodily' brain regions, implying a different mode of emotion processing. This may be related to their tendency to experience physical symptoms.

\section{Declaration of interest}

None.
Alexithymia is a multifaceted personality construct, which collectively represents a deficit in the cognitive processing of affects that predisposes to several physical and psychiatric illnesses, ${ }^{1}$ and it has especially been linked with somatisation. ${ }^{2}$ The salient features of alexithymia include a difficulty in describing and identifying one's feelings, difficulty in distinguishing feelings from bodily sensations of emotional arousal, limited imaginal capacities and an externally oriented cognitive style. ${ }^{3}$ Thus, it has also been called 'blindfeel' (analogous to 'blindsight'). ${ }^{4}$ However, little is known about the brain mechanisms by which this feature predisposes individuals to somatic symptoms and illness.

The aim of our study was to investigate brain activations in response to emotional film stimuli in women with alexithymia and to compare them with corresponding activations in women without this condition. We predicted that individuals with alexithymia would exhibit less activation in the anterior cingulate cortex. We chose to study women because most of the clinical phenomena associated with alexithymia - somatisation, depression, anxiety and eating disorders - are more prevalent among women than men. There is also evidence that the neural processing of emotions is different between men and women. ${ }^{5}$ We used film clips instead of still pictures as emotional stimuli because the prolonged and engaging nature of these stimuli enables access to the possible individual differences in emotional involvement better than static images do.

\section{Method}

\section{Participants}

The participants were adult students recruited into the study on the basis of their scores on the 20-item Toronto Alexithymia Scale (TAS-20) ${ }^{6,7}$ This self-report scale consists of 20 statements, and it is the most commonly used scale to assess alexithymia. ${ }^{8}$ It has been validated with a large, population-based Finnish sample. ${ }^{9}$
In addition, the revised form of the Symptom Checklist-90 (SCL-90-R) was used to exclude people with clinically significant levels of psychiatric symptoms, defined by reference to the normative levels of a large Finnish out-patient sample. ${ }^{10}$ The participants had to score below 1.50 on the SCL-90. After this, the research psychiatrist briefly interviewed the participants about previous or current psychiatric illness or treatment. Psychiatric or other medical disorder and medication, left-handedness and possible metal objects in the body were further exclusion criteria.

Two experimental groups were formed: 10 women with alexithymia (mean TAS-20 total score 62.40 , s.d. $=1.58$ ) and 11 women without alexithymia (mean score 38.55 , s.d. $=5.32$ ). The difference in alexithymia scores was highly significant between the groups $\left(F_{(1,19)}=185.60, P<0.001\right)$. The mean ages of these groups were 35.20 years $($ s.d. $=5.51)$ and 34.90 years $($ s.d. $=7.01)$ respectively, providing no statistically significant difference $\left(F_{(1,19)}=0.011\right.$, $P=0.92)$. There was also no difference in the duration of education between the groups $\left(F_{(1,19)}=0.33, P=0.57\right)$, with mean values of 15.10 years $($ s.d. $=6.10)$ and 15.00 years $($ s.d. $=3.54)$ respectively.

The study was approved by the ethics committee of Turku University/Turku University Central Hospital. All participants were given a detailed description of the study procedure and gave written informed consent.

\section{Stimulus materials and apparatus}

The stimulus material consisted of four brief films for each of the three emotional conditions (neutral, amusement, sadness), i.e. 12 films in total; their average length was $2.5 \mathrm{~min}$. Four of the film clips were chosen from a previously validated set of films ${ }^{11,12}$ and the rest were chosen from film material of similar kind for the purposes of this study. All the film clips were validated for their emotional content in a sample of 51 university students, using a self-rating design comparable with the present study. All 
the films are described in an earlier paper. ${ }^{13}$ The neutral films were chosen from an assortment of professional video material with the aim of minimising emotional content and maximising similarity with the emotional films in terms of basic sensory properties, i.e. they contained movement (such as people walking in the park), natural colours (outside and inside scenes) and music, as did the emotional films. The films were projected onto a video screen, which was placed at a distance of $2 \mathrm{~m}$ from the participant in such a position that it allowed comfortable viewing by the person while reposing in a supine position in the positron emission tomography (PET) scanner.

\section{Subjective emotional ratings}

\section{Measurement of the intensity of the emotional experience}

To achieve self-ratings of emotions that were as reliable as possible, we paid special attention to the measurement of the intensity of emotional experience. Therefore, all the emotional self-ratings of the study (mood before the experiment and emotional ratings after the films) were done using Borg's Category Ratio scale, ${ }^{14,15}$ which is an instrument for the measurement of experiential intensity with validated verbal anchors throughout it. The range of the scale is from 0 (not at all) to 10 (extreme intensity), and there are detailed standard instructions for the rating procedure. There is also a standard procedure for practising the rating and for assessing the participant's ability to rate with the scale. This was done with stimulus material consisting of varying degrees (10\% to $90 \%$ ) of blackness according to the Natural Colour System used as the Swedish standard for colour. ${ }^{16,17}$ The participants made 18 ratings of blackness, and ratings in the range of 2 s.d. of the normative sample were accepted as verification that they were able to use the scale correctly.

\section{Mood before the experiment}

To exclude the possible effect of mood on emotional ratings, the mood state of all participants was controlled before the experiment with 18 mood items, which were chosen on the basis of studies on mood structure. ${ }^{18,19}$ Two types of positive and negative affect words were chosen: ones with more and ones with fewer arousal components. The chosen dimensions were active positive affect (humorous, active, excited, energetic), passive positive affect (relaxed, serene, happy, joyful), active negative affect (anxious, fearful, angry, disgusted) and passive negative affect (depressed, sad, dull, passive). Because these dimensions are consistent findings in previous empirical studies ${ }^{20,21}$ we did not validate these scales before the study. However, the scales seemed to work well enough for the purposes of our study, as the Cronbach alpha values for the four scales were $0.84,0.83,0.83$ and 0.65 respectively. The values for total positive and negative affect were $\alpha=0.92$ and $\alpha=0.86$ respectively. In addition, interest and boredom were elicited with single items.

\section{Self-ratings of emotions after the films}

To assess the possible differences in emotional involvement and attention during the films, after viewing each film the participants rated the target emotional states (amusement, sadness) and five covariate emotional states (interest, fear, anger, disgust and joy). These covariate emotional states were chosen to cover all the basic emotions, the properties of which are described by Frijda et al..$^{22}$ The basic emotions (or their near derivatives) are the most probable covariate emotions in all kinds of emotional films. In addition, in order to catch the emotional involvement in more than just one experiential dimension, three modalities of emotional state were rated: core relational theme, action readiness and feeling. ${ }^{19,22,23}$ The results for target emotional states and interest are reported in this study, but the ratings of the other covariate emotions were also checked to ensure that the films actually evoked the target emotions. The items for amusement were 'Humorous or funny things happened' (core relational theme), 'I wanted to smile or laugh' (action readiness) and 'I felt amused' (feeling). The items for sadness were 'Something important was lost' (core relational theme), 'I wanted to comfort' (action readiness) and 'I felt sad' (feeling). The items for interest were respectively 'Something important happened', 'I wanted to pay attention and understand' and 'I was interested'. These items and items for the covariate emotions were chosen from the previous studies. ${ }^{22,23}$ The interest dimensions were chosen especially for attention control during the films. The Cronbach $\alpha$ values for these scales across the target films were 0.97 for sadness, 0.92 for amusement, 0.95 for interest in sadness films, and 0.80 for interest in amusement films.

\section{Image acquisition}

For PET scanning, head fixation was done using a commercial head holder (General Electric, Milwaukee, Wisconsin, USA). The position of the head was secured with two beams of laser light and landmarks on the skin. Scans of the distribution of $\left[{ }^{15} \mathrm{O}\right] \mathrm{H}_{2} \mathrm{O}$ were acquired using a whole-body PET scanner (GE Advance, General Electric) operated in three-dimensional mode with $4.25 \mathrm{~mm}$ axial resolution and $2 \mathrm{~mm}$ coronal and sagittal resolution, providing 35 slices covering the whole brain. A transmission scan for attenuation correction was performed with tworod sources filled originally with $400 \mathrm{MBq}$ radioactivity $\left({ }^{68} \mathrm{Ge} /{ }^{68} \mathrm{Ga}\right)$. The films started to run $30 \mathrm{~s}$ before a $10 \mathrm{ml}$ bolus of $\left[{ }^{15} \mathrm{O}\right] \mathrm{H}_{2} \mathrm{O}(300 \mathrm{MBq})$ was injected into the left antecubital vein. Emission data acquisition was started when the true coincidence rate exceeded 15 kilocounts per second.

\section{Procedure}

After being informed about the experimental procedure and giving written consent, participants were instructed how to rate the intensity of their emotional experience, and the 'blackness' test was performed both as practice and as a check. After adequate performance on this test, the participants rated their current mood on the scale. Before viewing the films, the participants were instructed to rate their emotional state with regard to certain thoughts (core relational themes), urges (action readiness) and feelings evoked by the films as honestly as possible. The items on these dimensions of emotional experience were projected one by one on the screen immediately after each film clip, and the participants verbally reported their score on the Category Ratio 10-point scale for each item aloud. A copy of the scale was positioned beside the screen to allow the participants to have a constant view of the scoring options. The rating procedure lasted $1.5 \mathrm{~min}$ on average. Because of technical limitations the order of the films was random but fixed, i.e. the design was pseudorandom. After the experiment, participants were given an opportunity to ask questions about the study.

\section{Data analysis}

\section{Software}

For image realignment, normalisation and smoothing, and for creating statistical maps of the significant changes in regional cerebral blood flow, we used the Statistical Parametric Mapping software (SPM2; Wellcome Department of Cognitive Neurology, Institute of Neurology, University College London, UK) with 
Matlab version 6.1 (The MathWorks, Natick, Massachusetts, USA). The subjective emotional rating data were analysed with the Statistical Procedures for the Social Sciences software version 12.0.1 for Windows.

\section{Image preprocessing}

Before image preprocessing, the origin of each image was set manually to anterior commissure, and the anterior-posterior commissure line was checked to be horizontal. For motion correction, the second neutral image was chosen as a reference image to determine the rigid body transformation parameters, and the reslice interpolation method was fourth-degree B-spline. For spatial normalisation the non-weighted mean image of the realigned images was used as a source image and the non-weighted standard template as a template image. A total of 16 iterations of global non-linear warping were done with a $25 \mathrm{~mm}$ cut-off threshold for three-dimensional discrete cosine transform basis functions and with medium regularisation. The normalised images were smoothed using $12 \mathrm{~mm}$ full-width at half-maximum Gaussian filter.

\section{Statistical treatment of PET data}

To detect possible differences in brain responses to the emotional stimuli between the groups, a multistaged random effects model with a balanced design was used as the general approach. ${ }^{24}$ In the first stage, a multiple-subject, subject-separable general linear model with three conditions (neutral, amusement, sadness) was fitted, after which amusement-neutral and sadness-neutral contrast images for each participant were produced. The global cerebral blood flow effects were controlled with analysis of covariance (ANCOVA) by participant, and the mean global value was set to $50 \mathrm{ml} / \mathrm{min}$ per dl. Because of the pseudo-random experimental design, the linear effect based on the order of the films was also controlled as a nuisance variable with a subject-separable ANCOVA model. In the second stage, the contrast images of each condition were fed to the independent samples $t$-test, and the possible group differences were modelled in both directions, i.e. the contrast images of the alexithymia group were subtracted from the images of the control group and vice versa. The explorative whole-head model was fitted first, followed by the analyses of the medial prefrontal cortex, anterior cingulate gyrus, subcallosal cingulate cortex, amygdala and basal ganglia, including putamen and globus pallidus, but omitting the nucleus caudatus. The explicit mask images for these areas were generated with the MRIcro software ${ }^{25}$ by an experienced neurologist. The rationale for choosing these areas was based on a meta-analysis of emotional activations in PET and functional magnetic resonance imaging (fMRI) studies. ${ }^{26}$ All analyses were first performed separately for each condition (amusement, sadness). After checking for valence-specific effects, the conditions were combined into a general emotionprocessing condition. Because this combined condition included one paired measure per individual, violating the independence assumptions behind the independent samples $t$-test, the repeated measures and non-sphericity corrections supplied by SPM2 were applied in these analyses. The group differences in this combined condition are analogous to the main between-participant effect in repeated-measures analysis of variance (ANOVA). All coordinates of the supra-threshold clusters or peaks obtained were transformed from the Montreal Neurological Institute (MNI) space to the Talairach and Tournoux stereotaxic space.

\section{Choice of statistical thresholds}

Two types of possible group differences were searched for with the explorative whole-head analyses. First, we searched the specific peak activity differences by setting the height threshold high (corrected 0.05, false discovery rate) and the extent threshold low (uncorrected 0.05). Second, we also searched larger unspecific cluster activation differences by setting the height threshold low (uncorrected 0.05) and extent threshold high (corrected 0.05, false discovery rate). This was done because the emotional films are complex and multimodal stimuli which may activate large brain areas rather than specific regions. ${ }^{26}$ In region of interest analyses the height and extent of the statistical thresholds were set to 0.001 voxels and 7 voxels respectively, uncorrected. These thresholds have been previously used in a similar analysis. ${ }^{27}$

\section{Subjective emotional ratings}

Mood. The possible differences of mood between the alexithymia and control groups before the experiment were checked with one-way ANOVAs for each mood separately.

Target emotions. The possible differences in emotional ratings after the films were checked with $3 \times 3 \times 2$ repeated-measures ANOVAs. Each emotion (amusement, sadness, interest) was analysed separately. The 'within' factor consisted of the three mean emotional ratings (core relational theme, action readiness, feeling) in each emotion film category (neutral, amusement, sadness) and the 'between' factor consisted of the experimental groups (alexithymia, control). The within effect served as a manipulation check and the within-between interactions revealed the possible group differences. Special contrast (simple) was designed in such a way that the mean ratings of emotional components in the neutral films served as a reference against which the corresponding mean ratings of the amusement and sadness films were compared separately. This design is analogous to the subtraction approach of SPM modelling in that emotional responsiveness is modelled as incremental activity over neutral stimuli. The formation of contrast images follows the subtraction logic, ${ }^{28}$ and the analyses of the experiential emotional activations during the experiment are thus parallel to the analyses of the concomitant regional cerebral blood flow activations during the experiment. In addition, both total emotion (the mean of the three emotional components) and each modality in turn were checked for this contrast.

\section{Covariate emotions}

Similar analyses to those described above were applied to the covariate emotions. In addition, to check whether the intended target emotional ratings (i.e. the emotional components of amusement or sadness) were the highest in the corresponding films, and whether the groups differed in covariate ratings, $3 \times 7 \times 2$ repeated-measures ANOVAs were conducted for ratings in amusement and sadness films separately. The 'within' factor consisted of the three mean emotional ratings (core relational theme, action readiness, feeling) of each emotion and simple contrast was designed in such a way that the target emotional ratings served as a reference block against which the other emotional rating blocks were compared separately.

\section{Results}

\section{Mood before the experiment}

There was no statistically significant group difference in mood before the experiment. However, the group effects on boredom (alexithymia $1.80 \mathrm{v}$. non-alexithymia $0.73 ; F_{(1,19)}=4.12, P=0.06$ ) 
and interest (alexithymia $8.50 \mathrm{v}$. non-alexithymia $7.36, F_{(1,19)}=$ 2.52, $P=0.12$ ) approached significance. Thus there was some ambivalence in the ratings made by the participants with alexithymia: while reporting high interest these women also tended to report more intensive boredom compared with the nonalexithymia group. However, the intensity level of this boredom rating was still low (1.80), equivalent to 'very weak-weak' verbal intensity descriptions in the Category Ratio scale. In any case, the differences between the groups in mood were so small that they are unlikely to explain the results of the experiment.

\section{Self-ratings of emotions after the films}

\section{Target emotions}

Self-ratings of amusement on the three emotional modalities increased after the amusement films $\left(F_{(1,19)}=55.69, P<0.001\right)$ and there was no significant self-rating $\times$ group interaction on either the total scale of amusement or any of its components, the highest $F$ being $0.94, P=0.36$. Similarly, the self-ratings of sadness increased after the sadness films $\left(F_{(1,19)}=119.25, P<0.001\right)$ and there was no significant self-rating $\times$ group interaction, the highest $F$ being $1.96, P=0.18$. Also, the self-ratings of interest increased after both the amusement and the sadness films: $F_{(1,19)}=11.70$, $P<0.01$ and $F_{(1,19)}=68.67, P<0.001$ respectively. There was no statistically significant self-rating $\times$ group interaction on interest or its components, the highest $F$ being $1.79, P=0.20$.

\section{Covariate emotions}

Both emotional film types evoked higher covariate emotional ratings than neutral films, except the fear ratings after amusement films (no effect) and joy ratings after sadness films (lower effect). However, when compared with the target emotional ratings, each covariate emotional rating was lower, the lowest $F_{(1,20)}$ being 9.68 , $P=0.006$. There were some differences between the alexithymia and non-alexithymia groups in covariate emotional ratings: participants in the alexithymia group rated more intensive anger components after humorous films $\left(F_{(1,19)}=4.84, P<0.05\right)$, and their ratings of threat (core relational theme of fear) were relatively higher in neutral films compared with humorous films $\left(F_{(1,19)}=6.29, P<0.05\right)$. Those in the alexithymia group also rated more intensive disgust components after sadness films $\left(F_{(1,19)}=\right.$ 6.15, $P<0.05)$; in particular the action readiness component of disgust (shivering) was higher than other components $\left(F_{(1,19)}=\right.$ 6.06, $P<0.05)$.

To sum up, the emotional experiences of amusement, sadness and interest varied according to the intended emotional inductions throughout the experiment for all participants, and there was no group difference in this variation. However, films induced also lower levels of covariate emotions and the groups differed in these ratings. Compared with the non-alexithymia group, participants with alexithymia reported more anger after amusement films and more disgust (especially its action readiness component) after sadness films. They also gave a relatively high rating to the threat component after neutral films.

\section{Differences in cerebral blood flow between groups}

\section{Valence-specific effects}

All analyses were first performed on both types of contrast images (amusement-neutral, sadness-neutral) separately. No specific peak activity difference was found for the groups. However, differences in large cluster activation emerged for the groups in both amusement and sadness conditions. Because there was no difference in cluster locations between amusement and sadness, the conditions were combined and these results are reported as a whole in the next section under the label of emotional processing.

\section{Differences in emotional processing}

Whole-brain exploration. Differences in large cluster activations emerged between the groups in both directions. During the combined emotional films, the alexithymia group had lower activation in large parts of the occipital and posterior lobes in comparison with the non-alexithymia group, forming two clusters, one for each hemisphere (Fig. 1). The three peak activations for each cluster are presented in Table 1 . There were also two large higheractivation clusters for the alexithymia group, located mainly in the middle and left-side parts of the brain (Fig. 2). The three peak activations for each cluster are presented in Table 2.

Region of interest analyses. There was one significant difference in peak activation in the right anterior cingulate gyrus (Fig. 3, Table 1) and one nearly significant difference in the left superior frontal/middle frontal gyrus (Fig. 4, Table 1). In both of these areas activations were lower in the alexithymia group compared with the non-alexithymia group.

\section{Discussion}

The main finding of this study is that, despite the similarly experienced intensity of the central components of emotion, the brains of the women with alexithymia processed emotion-eliciting stimuli differently from the brains of those in the non-alexithymia group. The motor and somatosensory areas were activated to a greater extent, and the anterior cingulate cortex to a lesser extent, in the alexithymia group. This could be related to the tendency of people with alexithymia to experience bodily sensations in an emotion-provoking situation. These findings also correspond to the areas involved in interoception, that is, the 'feeling' of the body state. According to Craig, ${ }^{29}$ this afferent path represents the physiological condition of all tissues in the body. This includes both distinct sensations engendered in the interoceptive and anterior insular cortex as well as affective motivations engendered in the anterior cingulate cortex. It seems that there is a disruption of these functions in alexithymia, and that this phenomenon may, in the long run, lead to the tendency of individuals with this condition to develop 'psychosomatic' symptoms.

According to a hypothesis by Lane et al, ${ }^{4}$ environmental events trigger an emotional response that is associated with an impoverished conscious experience of emotion in individuals with alexithymia. Instead, these individuals manifest behavioural and autonomic responses, including probably a heightened awareness of bodily sensations. This theory of alexithymia suggests that people with this condition exhibit less activation in the anterior cingulate cortex, an area known to have a role in the capacity to experience emotion in a differentiated and complex way, ${ }^{30}$ and this assumption has indeed been supported by two previous imaging studies. ${ }^{27,31}$ Our study also confirms this finding. However, the mechanism of one of the two other features of alexithymia, namely the tendency to perceive bodily ('psychosomatic') sensations instead of emotions, has not been previously demonstrated in an imaging study.

Compared with people with alexithymia, those without this condition will activate their visual pathways to a greater extent. In a meta-analysis ${ }^{26}$ of emotion processing among healthy individuals, combining the results of 55 PET and fMRI studies, the authors demonstrated that the occipital cortex (mainly Brodmann areas 18 and 19) is activated by visual induction. It has been 


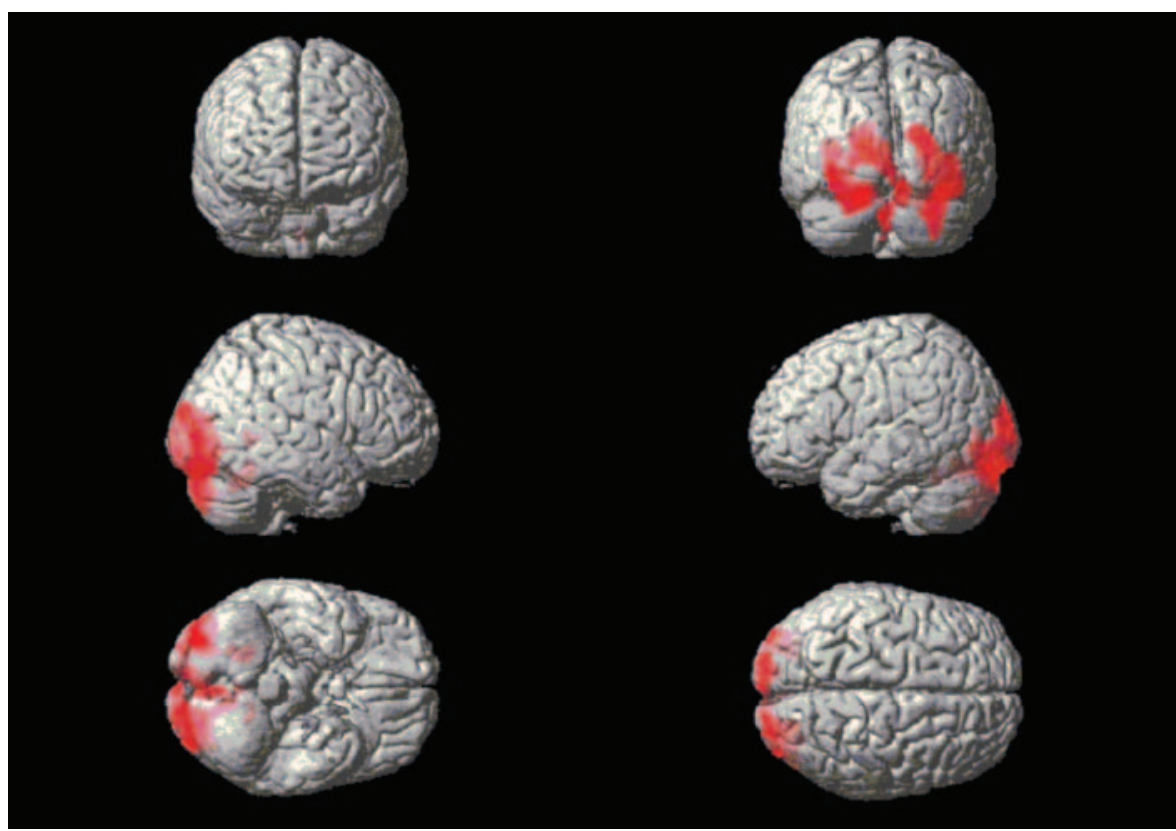

Fig. 1 Brain areas exhibiting less activation in the participants with alexithymia.

\begin{tabular}{|c|c|c|c|c|c|c|}
\hline \multirow[b]{2}{*}{ Cluster size } & \multirow[b]{2}{*}{ Brain region } & \multicolumn{3}{|c|}{ Talairach and Tournoux coordinates } & \multirow[b]{2}{*}{$t_{\max }{ }^{a}$} & \multirow[b]{2}{*}{$z$} \\
\hline & & $x$ & $y$ & $z$ & & \\
\hline \multicolumn{7}{|c|}{ Whole brain exploratory analyses } \\
\hline \multirow[t]{3}{*}{2903} & Right posterior lobe, cuneus & 24 & -79 & 13 & $4.94 * \mathrm{~b}$ & 4.34 \\
\hline & Right posterior lobe, uvula & 30 & -83 & 23 & $4.60 * \mathrm{~b}$ & 4.10 \\
\hline & Right occipital lobe, cuneus (BA19/18) & 18 & -96 & 23 & $4.38^{* \mathrm{~b}}$ & 3.93 \\
\hline \multirow[t]{3}{*}{3502} & Left occipital lobe, cuneus (BA18) & -16 & -96 & 18 & $4.77 *^{\mathrm{b}}$ & 4.22 \\
\hline & Left occipital lobe, fusiform gyrus (BA18) & -22 & -90 & -17 & $4.65^{\star b}$ & 4.13 \\
\hline & Left occipital lobe, middle occipital gyrus (BA19) & -36 & -93 & 14 & $4.55^{\star b}$ & 4.06 \\
\hline \multicolumn{7}{|c|}{ Region of interest analyses } \\
\hline 20 & Right limbic lobe, anterior cingulate & 14 & 30 & 26 & $4.54^{3}$ & 4.05 \\
\hline 35 & Left frontal lobe, superior frontal gyrus (BA8)/middle frontal gyrus (BA6) & -32 & 22 & 54 & 4.27 & 3.85 \\
\hline \multicolumn{7}{|c|}{$\begin{array}{l}\text { BA, Brodmann area. } \\
\text { a. d.f. }=40 \text {. } \\
\text { b. Corrected (family-wise error rate). } \\
\text { c. Corrected (false discovery rate). } \\
{ }^{*} P<0.05 \text {. }\end{array}$} \\
\hline
\end{tabular}

proposed that the occipital cortex is involved in the processing of visually relevant, complex emotional stimuli. ${ }^{32}$ These activations of the visual cortex are also independent of the type of emotion. This is fully in accordance with our results, which showed that people in the non-alexithymia group activated to a greater extent than the alexithymia group large dorsal areas, including the cuneus, uvula and fusiform gyrus, in response to emotional films.

There was also distinct left-sided lateralisation visible in the brain activation of the alexithymia group. According to the older theories of emotion, the left hemisphere is specialised in cognitive processing and the right hemisphere in the processing of emotion. However, in a meta-analysis of healthy people ${ }^{33}$ the authors found no support for the hypothesis of overall right lateralisation of emotion processing. It could be that the normal balance between the hemispheres is lost in alexithymia, and that individuals with this condition thus exhibit relatively more left-sided activations. Some evidence in favour of this view exists. Several studies have suggested left hemisphere dominance in participants with alexithymia. ${ }^{34-36}$ Deficits in the perception of emotion have also been found in people with right hemisphere damage. . $^{37,38}$

One of the reasons for our results being to some extent different from the previous imaging studies could be that we used film clips instead of pictures. Because films create a more prolonged and engaging emotional response, they may simulate real-life emotional situations better than static pictures do. There are also several limitations to our study, including its small sample size, with exclusively female participants, and the use of a self-report measure to assess alexithymia. Our results should be replicated with other methods of assessment of alexithymia, including structured interviews such as the recently developed Toronto Structured Interview for Alexithymia, ${ }^{39}$ or reliable projective methods such as the Levels of Emotional Awareness Scale, ${ }^{40}$ and possibly a larger sample.

In conclusion, our study shows that alexithymia is related both to impairment in the processing of emotions (less activation in the anterior cingulate) and to a tendency to activate brain areas relating to bodily sensations in emotion-evoking situations. 


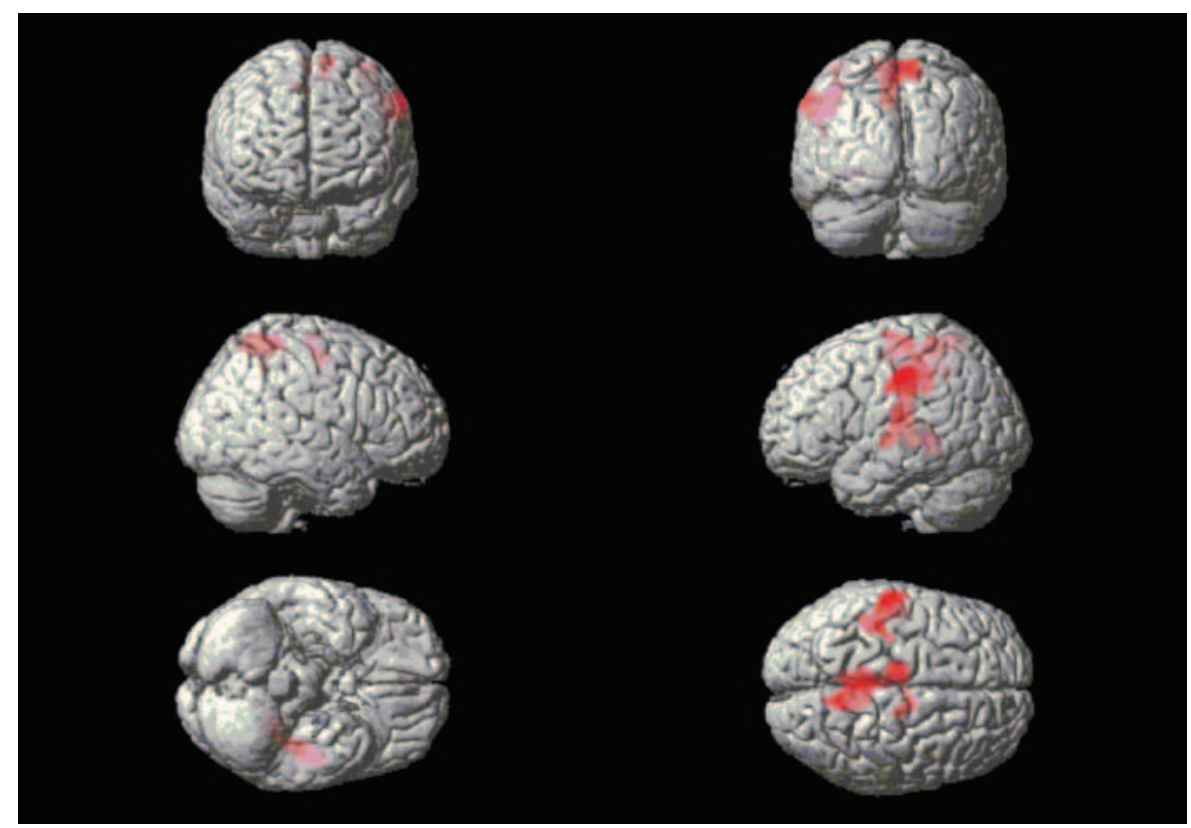

Fig. 2 Brain areas exhibiting more activation in the participants with alexithymia.

\begin{tabular}{|c|c|c|c|c|c|c|}
\hline \multirow[b]{2}{*}{ Cluster size } & \multirow[b]{2}{*}{ Brain region } & \multicolumn{3}{|c|}{ Talairach and Tournoux coordinates } & \multirow[b]{2}{*}{$t_{\max }{ }^{a}$} & \multirow[b]{2}{*}{$z$} \\
\hline & & $x$ & $y$ & $z$ & & \\
\hline $1942^{*}$ & $\begin{array}{l}\text { Left frontal lobe, precentral gyrus (BA4) } \\
\text { Left sub-lobar insula (BA13) } \\
\text { Left temporal lobe, sub-gyral }\end{array}$ & $\begin{array}{l}-57 \\
-46 \\
-26\end{array}$ & $\begin{array}{l}-19 \\
-21 \\
-43\end{array}$ & $\begin{array}{r}38 \\
14 \\
-1\end{array}$ & $\begin{array}{l}6.60^{*} \\
4.32^{*} \\
4.28^{*}\end{array}$ & $\begin{array}{l}5.40 \\
3.89 \\
3.86\end{array}$ \\
\hline $3502^{*}$ & $\begin{array}{l}\text { Right parietal lobe, precuneus (BA7) } \\
\text { Left frontal lobe, superior frontal gyrus (BA6) } \\
\text { Left frontal lobe, medial frontal gyrus }\end{array}$ & $\begin{array}{r}8 \\
-12 \\
-10\end{array}$ & $\begin{array}{l}-49 \\
-12 \\
-17\end{array}$ & $\begin{array}{l}60 \\
65 \\
56\end{array}$ & $\begin{array}{l}4.90^{*} \\
4.61^{*} \\
4.32^{*}\end{array}$ & $\begin{array}{l}4.31 \\
4.10 \\
3.89\end{array}$ \\
\hline $\begin{array}{l}\text { BA, Brodmann } \\
\text { a. d.f. }=40 \text {. } \\
\star P<0.05 \text { correc }\end{array}$ & & & & & & \\
\hline
\end{tabular}
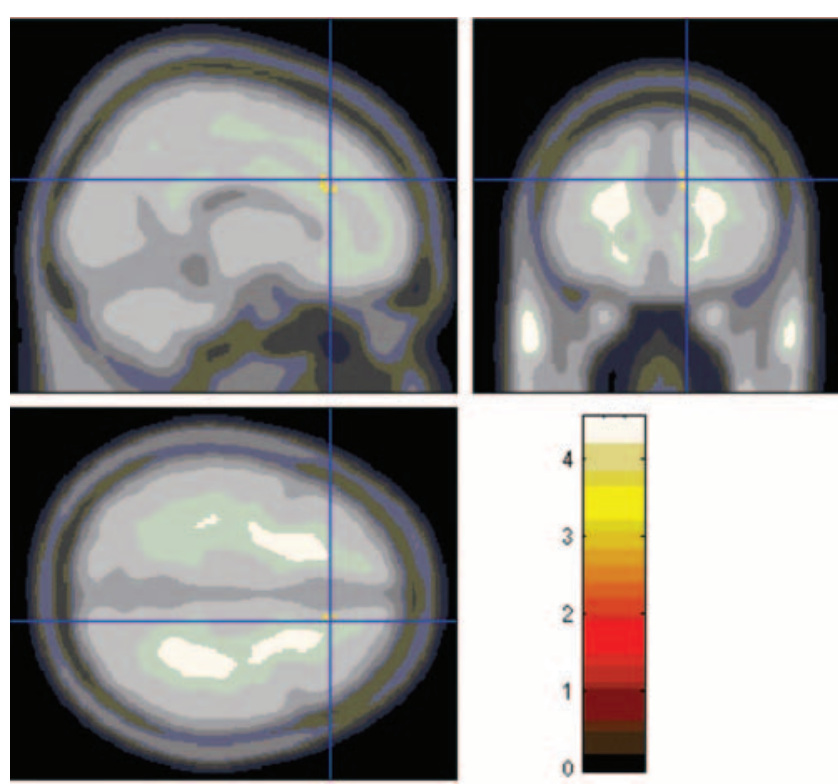

Fig. 3 Lesser activation in the anterior cingulate cortex, seen in the participants with alexithymia.
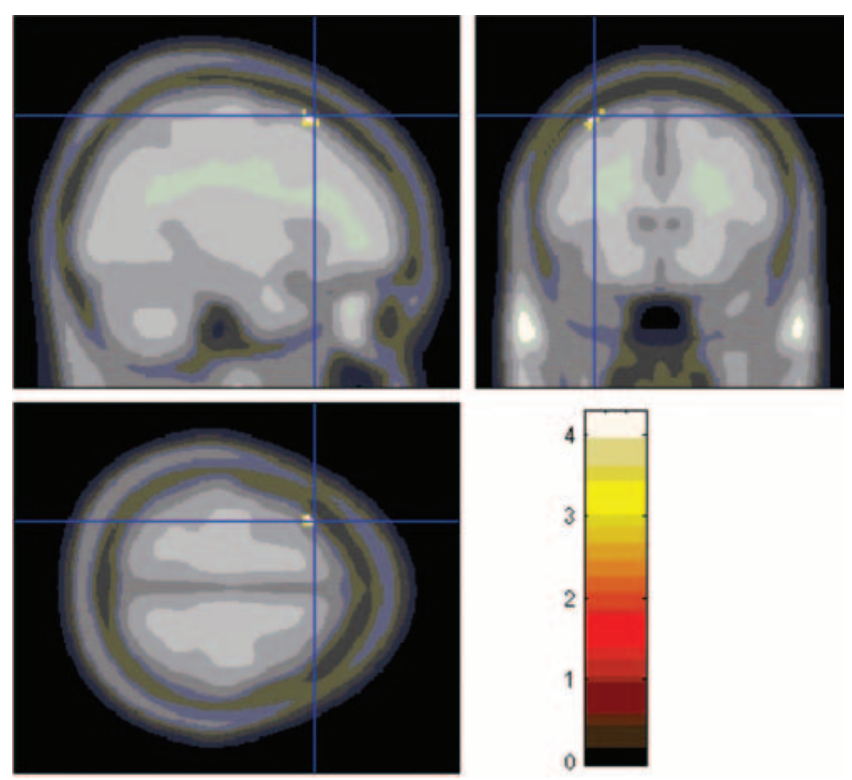

Fig. 4 Lesser activation in the superior/middle frontal gyrus, seen in participants with alexithymia. 
Hasse Karlsson, Department of Psychiatry, University of Helsinki, Department of Psychiatry, and National PET Centre, Turku University Central Hospital, Turku; Petri Näätänen, Department of Psychology, University of Helsinki; Hanna Stenman, Department of Psychiatry, University of Turku, Turku, Finland

Correspondence: Hasse Karlsson, Department of Psychiatry, University of Helsinki, 00014 Helsinki, Finalnd. Email: hasse.karlsson@helsinki.fi

First received 15 December 2006, final revision 19 June 2007, accepted 6 July 2007

\section{Acknowledgements}

The study was funded by the Signe and Ane Gyllenberg Foundation.

\section{References}

1 Taylor GJ, Bagby RM, Parker JDA. Disorders of Affect Regulation. Alexithymia in Medical and Psychiatric Illness. Cambridge University Press, 1997.

2 De Gucht V, Heiser W. Alexithymia and somatization. A quantitative review of the literature. J Psychosom Res 2003; 54: 425-34.

3 Nemiah JC, Freyberger H, Sifneos PE. Alexithymia: a view of the psychosomatic process. In Modern Trends in Psychosomatic Medicine (ed OW Hill: vol. 3, 430-9. Butterworths, 1976.

4 Lane RD, Ahern GL, Schwartz GE, Kaszniak AW. Is alexithymia the emotional equivalent of blindsight? Biol Psychiatry 1997; 42: 834-44.

5 George MS, Ketter TA, Parekh PI, Herscovitch P, Post RM. Gender differences in regional cerebral blood flow during transient self-induced sadness or happiness. Biol Psychiatry 1996; 40: 859-71.

6 Bagby RM, Parker JDA, Taylor GJ. The twenty-item Toronto Alexithymia Scale Item selection and cross-validation of the factor structure. J Psychosom Res 1994; 38: 23-32.

7 Bagby RM, Taylor GJ, Parker JDA. The twenty-item Toronto Alexithymia Scale: II. Convergent, discriminant, and concurrent validity. J Psychosom Res 1994; 38: $33-40$.

8 Taylor GJ, Bagby RM, Parker JDA. The 20-item Toronto Alexithymia Scale IV. Reliability and factorial validity in different languages and cultures. J Psychosom Res 2003; 55: 277-83.

9 Joukamaa M, Miettunen J, Kokkonen P, Koskinen M, Julkunen J, Kauhanen J, Jokelainen J, Veijola J, Laeksy K, Järvelin M-R. Psychometric properties of the Finnish 20-item Toronto Alexithymia Scale. Nord J Psychiatry 2001; 55: 1237.

10 Holi MM, Sammallahti PR, Aalberg VA. A Finnish validation study of the SCL-90. Acta Psychr Scand 1998; 97: 42-6.

11 Gross JJ, Levenson RW. Emotion elicitation using films. Cogn Emot 1995; 9: 87-108.

12 Philippot P. Inducing and assessing differentiated emotion-feeling states in the laboratory. Cogn Emot 1993; 7: 171-93.

13 Aalto S, Näätänen $P$, Wallius E, Metsähonkala L, Stenman H, Niemi PM, Karlsson $\mathrm{H}$. Neuroanatomical substrata of amusement and sadness: a PET activation study using film stimuli. Neuroreport 2002; 13: 67-73.

14 Borg G. Borg's range model and scales. International J Sport Psychol 2001; 32: $110-26$.

15 Marks LE, Borg G, Ljunggren G Individual differences in perceived exertion assessed by two new methods. Percept Psychophys 1983; 34: 280-8.

16 Borg G, Borg E. A General Psychophysical Scale of Blackness and its Possibilities as a Test of Rating Behavior. Stockholm University, 1991.

17 Hård A. A new colour atlas based on the Natural Colour System by HeringJohansson. Farbe 1966; 15: 296-304.

18 Larsen RJ, Diener E. Promises and problems with the circumplex model of emotion. In Emotion. Review of Personality and Social Psychology (ed MS Clark): no. 13, 25-59. Sage, 1992.
19 Watson D, Tellegen A. Toward a consensual structure of mood. Psychol Bull 1985; 98: 219-35.

20 Russell JA, Lewicka M, Niit T. A cross-cultural study of a circumplex model of affect. J Pers Soc Psychol 1989; 57: 848-56.

21 Ekman P. An argument for basic emotions. Cogn Emot 1992; 6: 169-200.

22 Frijda $\mathrm{NH}$, Kuipers $\mathrm{P}$, ter Schure E. Relations among emotion, appraisal, and emotional action readiness. J Pers Soc Psychol 1989; 57: 212-28.

23 Smith CA, Lazarus RS. Appraisal components, core relational themes, and the emotions. Cogn Emot. 1993; 7: 233-69.

24 Penny WD, Holmes AP. Random effects analysis. In Human Brain Function (eds RSJ Frackowiak, KJ Friston, C Frith, R Dolan, CJ Price, S Zeki, J Ashburner, WD Penny): 843-500. Academic Press, 2003.

25 Rorden C, Brett M. Stereotaxic display of brain lesions. Behav Neurol 2000; 12: $191-200$.

26 Phan KL, Wager T, Taylor SF, Liberzon I. Functional neuroanatomy of emotion: a meta-analysis of emotion activation studies in PET and fMRI. Neurolmage 2002; 16: 331-48.

27 Berthoz S, Artiges E, Van de Moortele P-F, Poline J-B, Rouquette S, Consoli SM, Martinot J-L. Effect of impaired recognition and expression of emotions on frontocingulate cortices: an fMRI study of men with alexithymia. Am J Psychiatry 2002; 159: 961-7.

28 Friston KJ, Price CJ, Buchel C, Frackowiak RSJ. A taxonomy of study design. In Human Brain Function (eds RSJ Frackowiak, KJ Friston, C Frith, R Dolan, JC Mazziotta): 141-59. Academic, 1997.

29 Craig AD. Interoception: the sense of the physiological condition of the body. Curr Opin Neurobiol 2003; 13: 500-5.

30 Lane RD, Reiman EM, Axelrod B, Yun L-S, Holmes A, Schwartz GE. Neura correlates of levels of emotional awareness: evidence of an interaction between emotion and attention in the anterior cingulate cortex. J Cogn Neurosci 1998; 10: 525-35.

31 Kano M, Fukudo S, Gyoba J, Kamachi M, Tagawa M, Mochizuki H, Itoh M, Hongo $\mathrm{M}$, Yanai $\mathrm{K}$. Specific brain processing of facial expressions in people with alexithymia: an H2-150-PET study. Brain 2003; 126: 1474-84.

32 Lane RD, Reiman EM, Ahern GL, Schwartz GE, Davidson RJ, Friston KJ, Yun LS Chen $\mathrm{K}$. Neuroanatomical correlates of externally and internally generated human emotion. Am J Psychiatry 1997; 154: 918-25.

33 Wager TD, Phan KL, Liberzon I, Taylor SF. Valence, gender, and lateralization of functional brain anatomy in emotion: a meta-analysis of findings from neuroimaging. Neurolmage 2003; 19: 513-31.

34 Parker JDA, Taylor GJ, Bagby RM. Relationship between conjugate lateral eye movements and alexithymia. Psychother Psychosom 1992; 57: 94-101.

35 Berenbaum $\mathrm{H}$, Prince JD. Alexithymia: the interpretation of emotion-relevant information. Cogn Emot 1994; 8: 231-44.

36 Jessimer M, Markham R. Alexithymia: a right hemisphere dysfunction specific to recognition of certain facial expressions? Brain Cogn 1997; 34: 246-58.

37 Mandal MK, Borod JC, Asthana HS, Mohanty A, Mohanty S, Koff E. Effects of lesion variables and emotion type on the perception of facial emotion. J Nerv Ment Dis 1999; 187: 603-9.

38 Cicero BA, Borod JC, Santschi C, Erhan HM, Obler LK, Agosti RM, Welkowitz J Grunwald IS. Emotional versus nonemotional lexical perception in patients with right and left brain damage. Neuropsychiatry Neuropsychol Behav Neurol 1999; 12: 255-64.

39 Bagby RM, Taylor GJ, Parker JD, Dickens SE. The development of the Toronto Structured Interview for Alexithymia: item selection, factor structure, reliability and concurrent validity. Psychother Psychosom 2006; 75: 25-39

40 Lane RD, Quinlan DM, Schwartz GE, Walker PA, Zeitlin SB. The Levels of Emotional Awareness Scale: a cognitive-developmental measure of emotion. J Pers Assess 1990; 55: 124-34. 